\title{
麦季氮肥运筹对冬小麦-夏玉米种植体系物质生产及氮肥利用的影响
}

\author{
吴光磊 ${ }^{1,3}$ 曾 彦 $^{2}$ 郭立月 ${ }^{1} \quad$ 崔正勇 $^{1} \quad$ 李 $^{\text {勇 }}$ 尹 燕枰 $^{1}$ \\ 王振林 $1, *$ 蒋高明 $1,3, *$
}

${ }^{1}$ 山东农业大学 / 作物生物学国家重点实验室, 山东泰安 $271018 ;{ }^{2}$ 山东农业大学农业生态系统定位研究站, 山东临沂 $273317 ;{ }^{3}$ 中国 科学院植物研究所 / 植被与环境变化国家重点实验室, 北京 100093

摘 要: 2009-2011 年在山东临沂冬小麦-夏玉米生产田, 探讨了麦季施氮水平和施氮时期对两季作物干物质积累与 分配、籽粒产量、氮肥农学利用率和氮肥偏生产力的影响。施氮量设 4 个处理, 分别是 $0(\mathrm{~N} 0) 、 168.75(\mathrm{~N} 1) 、 225(\mathrm{~N} 2)$ 和 $281.25 \mathrm{~kg} \mathrm{hm}^{-2}$ (N3); 氮肥追施时期设 2 个处理, 分别为拔节期(S1)和拔节期+开花期(S2)。在 S1 条件下，冬小麦 和夏玉米的籽粒干物质积累量及夏玉米和周年生物产量均表现为 $\mathrm{N} 3>\mathrm{N} 2>\mathrm{N} 1$, 冬小麦和夏玉米的籽粒产量 N2 和 N3 处理间无显著差异; 氮肥农学利用率和氮肥偏生产力在麦季随施氮量增加显著降低, 而在玉米季则逐渐升高, 但玉 米季氮肥偏生产力 $\mathrm{N} 3$ 与 $\mathrm{N} 2$ 处理间无显著差异。 $\mathrm{S} 2$ 条件下麦季施氮量由 N2 处理增加 $25 \%$ (N3), 冬小麦和夏玉米籽 粒干物质积累量、生物产量和籽粒产量无显著变化, 氮肥农学利用率和氮肥偏生产力在麦季显著降低、在玉米季无 显著变化。与 $\mathrm{S} 1$ 相比, $\mathrm{S} 2$ 有利于提高 $\mathrm{N} 1$ 和 $\mathrm{N} 2$ 条件下冬小麦籽粒与营养器官的干物质积累量、生物产量、籽粒产 量和氮肥农学利用率及氮肥偏生产力, 但对 $\mathrm{N} 3$ 条件下的这些指标无显著影响; 而在玉米季, 3 个施氮量水平下夏玉 米的各项指标均显著升高。综合周年生物产量、籽粒产量和氮肥农学利用率及氮肥偏生产力结果, 麦季总施氮量 225 $\mathrm{kg} \mathrm{hm}^{-2}$ 及拔节期 + 开花期追氮是本试验条件和种植模式下的最佳麦季氮肥运筹模式。

关键词：冬小麦-夏玉米种植体系; 施氮量; 追氮时期; 产量; 氮肥利用率

\section{Effects of Nitrogen Management in Wheat Season on Matter Production and Nitrogen Use Efficiency in Winter Wheat-Summer Maize Rotation System}

\author{
WU Guang-Lei ${ }^{1,3}$, ZENG Yan ${ }^{2}$, GUO Li-Yue ${ }^{1}$, CUI Zheng-Yong ${ }^{1}$, LI Yong ${ }^{3}$, YIN Yan-Ping ${ }^{1}$, WANG \\ Zhen-Lin ${ }^{1, *}$, and JIANG Gao-Ming ${ }^{1,3, *}$

\footnotetext{
${ }^{1}$ State Key Laboratory of Crop Biology / College of Agronomy, Shandong Agricultural University, Tai'an 271018, China; ${ }^{2}$ Agroecosystem Research Station, Shandong Agricultural University, Linyi 273317, China; ${ }^{3}$ Laboratory of Vegetation and Environment Changes / Institute of Botany, Chinese
} \\ Academy of Sciences, Beijing 100093, China
}

\begin{abstract}
Management of nitrogen $(\mathrm{N})$ fertilizer is a constant topic in crop cultivation aiming at high-yield and good-quality production as well as environmental protection. In winter wheat-summer maize rotation system, $\mathrm{N}$ fertilizer input in the wheat season has a subsequent influence on the maize season. In this study, we carried out a two-year field experiment in Linyi of Shandong Province, China from 2009 to 2011 with treatments of four $\mathrm{N}$ application rates and two topdressing schemes. In the wheat season, the $\mathrm{N}$ application rates were $0(\mathrm{~N} 0), 168.75(\mathrm{~N} 1), 225(\mathrm{~N} 2)$, and $281.25 \mathrm{~kg} \mathrm{ha}^{-1}(\mathrm{~N} 3)$, and the topdressing $\mathrm{N}$ was given at jointing stage (S1) and jointing + anthesis stage (S2). In the maize season, $\mathrm{N}$ fertilizer of $60 \mathrm{~kg} \mathrm{ha}^{-1}$ was applied before sowing and $90 \mathrm{~kg}$ $\mathrm{ha}^{-1}$ at 12-leaf stage in all treatments except for N0 (no N applied in the maize season as well). The dry matter accumulation and distribution, grain yield, nitrogen agronomic use efficiency (NAUE), and nitrogen partial factor productivity (NPFP) were investigated in both wheat and maize seasons. Under the S1 condition, dry matter accumulations in grains of wheat and maize and the biomasses of maize as well as the biomass of both crops heightened with $\mathrm{N}$ rate increased, but the grain yields of wheat and maize had no significant differences between N2 and N3 treatments. As the N rate increased, NAUE and NPFP decreased in winter
\end{abstract}

本研究由国家自然科学基金项目(31271661), 国家重点基础研究发展计划(973)项目(2009CB118602)和国家公益性行业(农业)科研专项 (201203100)资助。

*通讯作者(Corresponding authors): 王振林, E-mail: zlwang@sdau.edu.cn, Tel: 0538-8241359; 蒋高明, E-mail: jianggm@126.com 第一作者联系方式: E-mail: leinxin670@163.com, Tel: 0538-8242839

Received(收稿日期): 2012-04-23; Accepted(接受日期): 2012-07-05; Published online(网络出版日期): 2012-09-10.

URL: http://www.cnki.net/kcms/detail/11.1809.S.20120910.1403.022.html 
wheat but increased gradually in summer maize; however, the difference in NPFP between N2 and N3 was not significant. Under the S2 condition, the dry matter accumulations in grain, biomasses, and grain yields of wheat and maize had no significant increases in $\mathrm{N} 3$ treatment compared to $\mathrm{N} 2$ treatment, although the $\mathrm{N}$ application amount was promoted by $25 \%$ in $\mathrm{N} 3$ treatment. The NAUE and NPFP of wheat decreased significantly due to the more distribution of dry matter in vegetative organs of wheat in N3 treatment than in N2 treatment; whereas, the NAUE and NPFP of maize had no significant changes. In the wheat season, compared to S1, S2 was favorable to increase dry matter accumulations in grain and vegetative organs, biomass, grain yield, NAUE, and NPFP of winter wheat in treatments N1 and N2, but had no significant effects in treatment N3; in the maize season, S2 showed positive effects on these indices of summer maize in treatments N1, N2, and N3. With the comprehensive consideration of total biomass and grain yield of wheat and maize, NAUE, and NPFP, total N fertilizer of $225 \mathrm{~kg} \mathrm{ha}^{-1}$ in wheat season associated with topdressing at jointing and anthesis stages of wheat are recommended as the optimal management mode in winter wheat-summer maize rotation system under similar conditions to this experiment.

Keywords: Winter wheat-summer maize rotation system; Nitrogen application rate; Topdressing stage; Yield; N-fertilizer use efficiency

作物生产最主要的过程是光合产物的积累、分 配、转运及最终经济产量的形成 ${ }^{[1]}$ 。已有很多关于 小麦、玉米物质积累、分配、转运和籽粒产量形成 的报道 ${ }^{[2-6]}$ 。有研究表明, 适量施氮提高了各株型小 麦的干物质平均增长速率和最大增长速率 $\left(R_{\max }\right)$, 缩 短了各株型小麦到达 $R_{\text {max }}$ 的时间，延长了各株型小 麦的缓增持续期。随施氮量增加, 小麦成熟期各器 官干物质积累量、花后营养器官干物质再分配量和 再分配率先增后降 ${ }^{[7]}$ 。夏玉米生长期间的干物质累 积在环境条件适宜的条件下遵从经典的 Logistic 生 长曲线, 但在温度、水、肥、盐等环境胁迫下将出 现不规则的多峰变化 ${ }^{[1]}$; 施氮肥和有机肥可以延长 干物质积累的旺盛时期, 使玉米干物质总量积累速 率最大的时刻推后 1 3 d, 增加干物质积累量 ${ }^{[8]}$ 。

小麦-玉米一年两熟是我国北方粮食产区的主 要栽培制度之一, 也是近年来各地“吨粮田”采用的 主要种植方式 ${ }^{[9]}$ 。研究表明, 玉米可以利用前茬小麦 残留的硝态氮 ${ }^{[10]}$, 利用率与根系生长发育及分布关 系密切 ${ }^{[11]}$ 。目前通行的推荐施肥方案大多未考虑残 留养分的作用, 仅有少数研究在检测前茬肥料残效 的基础上指导下茬作物肥料施用 ${ }^{[12-13]}$ 。明确前茬作 物肥料运筹对后茬作物产量形成和肥料利用率的调 控效应, 可为制定周年肥料施用方案提供理论依 据。本试验研究麦季氮肥运筹对冬小麦-夏玉米种植 体系干物质积累分配、生物产量与籽粒产量和氮肥 利用率的调控效应, 旨在为冬小麦-夏玉米种植体系 合理氮肥施用方案的制定提供理论依据和技术支持。

\section{1 材料与方法}

\section{1 试验设计}

试验于 2009-2010 年和 2010-2011 年在山东 省临沂市山东农业大学农业生态系统定位研究站 (35 $26^{\circ} 34^{\prime \prime} N, 117^{\circ} 49^{\prime} 13^{\prime \prime}$ E)进行。研究区域属暖温
带大陆性季风气候, 多年平均气温 $13.2^{\circ} \mathrm{C}$, 平均无 霜期 $212 \mathrm{~d}$, 平均年降水量 $770.2 \mathrm{~mm}$, 但麦季干旱少 雨, 玉米季降水充沛。2009 年 10 月冬小麦播种前, 供试土壤 $0 \sim 20 \mathrm{~cm}$ 土层土壤含有机质 $1.13 \%$, 全氮 0.74 $\mathrm{g} \mathrm{kg}^{-1}$ 、速效氮 $75.3 \mathrm{mg} \mathrm{kg}^{-1}$ 、速效磷 $11.0 \mathrm{mg} \mathrm{kg}$ 、 速效钾 $107.3 \mathrm{mg} \mathrm{kg}^{-1}$ 。两年度供试材料均为高产中 筋小麦品种泰农 18 和普通高产玉米品种郑单 958 。

两年度均在小麦生长季设 4 个施氮量和 2 个追 氮时期处理, 施氮量 4 个处理分别为 $0(\mathrm{~N} 0) 、 168.75$ (N1)、225.00 (N2)和 $281.25 \mathrm{~kg} \mathrm{hm}^{-2}$ (N3), 其中 N1 和 N3 分别是在 N2 基础上减少或增加 $25 \%$ 施氮量; 在基施总氮量 40\%的基础上, 追氮处理 S1 为拔节期 再施 $60 \%$ 氮肥(S1), 追氮处理 S2 为拔节期和开花期 分别施总氮量的 $40 \%$ 和 $20 \%$ (S2)。玉米生长季除麦 季不施氮处理继续不施氮肥外, 其余处理均施纯氮 $150 \mathrm{~kg} \mathrm{hm}^{-2}$ ，其中基施 $40 \%$ ，大喇叭口期追施 60\%。

小区面积为 $2.3 \mathrm{~m} \times 8.0 \mathrm{~m}$, 随机区组排列, 3 次重 复。磷、钾肥全部基施, 每公顷施磷肥 $\left(\mathrm{P}_{2} \mathrm{O}_{5}\right) 90 \mathrm{~kg}$ 、 钾肥 $\left(\mathrm{K}_{2} \mathrm{O}\right) 75 \mathrm{~kg}$ 。氮肥为尿素( 含 $\mathrm{N} 46 \%$ ), 磷肥为磷 酸二铵(含 $\mathrm{P}_{2} \mathrm{O}_{5} 46 \%$ ), 钾肥为硫酸钾(含 $\mathrm{K}_{2} \mathrm{O} 52 \%$ )。小 麦基本苗为 180000 株 $\mathrm{hm}^{-2}$, 玉米种植密度为 60000 株 $\mathrm{hm}^{-2}$ 。其他管理措施同高产大田。

2009 - 2010 年度，小麦于 2009 年 10 月 17 日播 种，2010年 6 月 17 日收获; 玉米于 2009 年 6 月 19 日播种，10 月 5 日收获。2010-2011 年度, 小麦于 2010 年 10 月 12 日播种, 2011 年 6 月 12 日收获; 玉 米于 2011 年 6 月 21 日播种, 10 月 4 日收获。

\section{2 干物质测定方法}

于小麦和玉米成熟期取代表性植株, 小麦季每 处理取样 45 株, 按籽粒、叶片、茎鞘、颖壳+穗轴 分样, 玉米季每处理取样 6 株, 按籽粒、叶片、茎秆、 叶鞘、苞叶、穗轴分样, 均为 3 次重复。所有样品 经 $105^{\circ} \mathrm{C}$ 杀青 $30 \mathrm{~min}, 80^{\circ} \mathrm{C}$ 下烘干至恒重, 称重。 
1.3 籽粒产量测定与氮肥利用率计算

至成熟期, 小麦季每小区取 $2.3 \mathrm{~m}^{2}$, 玉米季每 小区取 $9.2 \mathrm{~m}^{2}$ 用于测产, 3 次重复。

氮肥农学利用率 $\left(\mathrm{kg} \mathrm{kg}^{-1}\right)=$ (施氮区籽粒产量空白区籽粒产量)/施氮量 ${ }^{[14]}$;

氮肥偏生产力 $\left(\mathrm{kg} \mathrm{kg}^{-1}\right)=$ 施氮区产量/施氮量 ${ }^{[15]}$ 。

1.4 统计分析

采用 SPSS18.0 软件处理数据和统计分析, 用 LSD 法进行多重比较。用 SigmPlot 10.0 软件绘图。

\section{2 结果与分析}

2.1 麦季氮肥运筹对冬小麦-夏玉米成熟期干物 质积累与分配的影响

2.1.1 冬小麦成熟期千物质的积累与分配在小 麦成熟期, 不施氮处理的籽粒干物质积累量和分配 比例显著低于施氮处理; 茎鞘+叶片和颖壳+穗轴干 物质积累量亦显著低于施氮处理, 但其分配比例显 著高于施氮处理(表 1)。表明全生育期不施氮肥降低 了小麦成熟期籽粒和营养器官干物质积累量, 但提 高了营养器官的干物质分配比例, 限制了干物质在 籽粒中的分配。

同一施氮时期不同施氮量处理间比较, S1 条件 下, 随施氮量增加, 籽粒和营养器官的干物质积累 量均显著提高 $(\mathrm{N} 3>\mathrm{N} 2>\mathrm{N} 1) ; \mathrm{S} 2$ 条件下, 籽粒干物质 积累量 N3 与 $\mathrm{N} 2$ 无显著差异, 显著高于 $\mathrm{N} 1$ 处理, 而 营养器官干物质积累量表现为 $\mathrm{N} 3>\mathrm{N} 2>\mathrm{N} 1$ 。相同追 氮条件下, 籽粒和营养器官的干物质分配比例施氮 量处理间无显著差异(表 1)。以上结果表明, 施氮量 对小麦成熟期干物质积累与分配的调控效应因追氮
时期改变而表现不同，拔节期追施氮肥条件下，籽 粒和营养器官干物质积累量随施氮量的增加而提高, 但在拔节期+开花期追施氮肥条件下，施氮量由 N2 水平增加 $25 \%$ 对籽粒和营养器官的干物质积累无明 显促进作用。

同一施氮量不同施氮处理间比较, N1 和 N2 条 件下的籽粒和营养器官干物质积累量 S2>S1, N3 条 件下 $\mathrm{S} 1$ 与 $\mathrm{S} 2$ 无显著差异; 同一施氮量条件下, 各器 官干物质分配比例 S1 与 $\mathrm{S} 2$ 无显著差异。表明在中、 低施氮量条件下, 拔节期+开花期追氮较拔节期追 氮有利于提高冬小麦籽粒和营养器官的干物质积累 量, 但在高施氮量条件下, 籽粒和营养器官干物质 积累量对追氮时期反应不敏感。

2.1.2 夏玉米成熟期千物质的积累与分配在夏 玉米成熟期, 不施氮处理籽粒干物质积累量和分配 比例显著低于施氮处理, 茎鞘+叶片和苍叶+穗轴中 的干物质积累量亦显著低于施氮处理, 但其分配比 例高于施氮处理(表 2)。不施氮处理籽粒和营养器官 干物质积累量分别低于施氮处理 $70.5 \%$ 109.1\%和 $47.3 \% \sim 72.3 \%$ ，表明麦季和玉米季不施氮肥显著降 低了夏玉米成熟期籽粒和营养器官干物质积累量, 降低了玉米籽粒干物质分配比例。

同一施氮时期不同施氮量处理间比较, S1 条件 下, 随麦季施氮量增加, 夏玉米籽粒干物质积累量 显著提高, 营养器官干物质积累量为 $\mathrm{N} 3 、 \mathrm{~N} 2>\mathrm{N} 1$; 干物质分配比例处理间无显著差异。S2 条件下, 籽 粒干物质积累量为 $\mathrm{N} 3 、 \mathrm{~N} 2>\mathrm{N} 1$, 营养器官干物质积 累量为 $\mathrm{N} 3>\mathrm{N} 2>\mathrm{N} 1$; 籽粒和营养器官干物质分配比 例 N2 与 N1、N3 均无显著差异(表 2)。以上结果表

表 1 冬小麦成熟期不同器官的干物质积累量与分配比例(2010-2011)

Table 1 Dry matter accumulation and distribution proportion in different organs of winter wheat at maturity (2010-2011)

\begin{tabular}{|c|c|c|c|c|c|c|c|c|c|}
\hline \multirow{2}{*}{\multicolumn{2}{|c|}{$\begin{array}{c}\text { 处理 } \\
\text { Treatment }\end{array}$}} & \multicolumn{4}{|c|}{ 积累量 Accumulation amount (g stalk $\left.{ }^{-1}\right)$} & \multicolumn{4}{|c|}{ 分配比例 Distribution proportion (\%) } \\
\hline & & $\mathrm{G}$ & $\mathrm{C}+\mathrm{S}+\mathrm{L}$ & $\mathrm{H}+\mathrm{A}$ & VO & G & $\mathrm{C}+\mathrm{S}+\mathrm{L}$ & $\mathrm{H}+\mathrm{A}$ & VO \\
\hline \multicolumn{2}{|c|}{ 对照 Control (N0) } & $1.22 \mathrm{e}$ & $1.02 \mathrm{e}$ & $0.43 \mathrm{~d}$ & $1.44 \mathrm{e}$ & $45.74 \mathrm{c}$ & $38.27 \mathrm{a}$ & $15.99 \mathrm{a}$ & $54.26 \mathrm{a}$ \\
\hline \multirow[t]{3}{*}{$\mathrm{S} 1$} & N1 & $1.69 \mathrm{~d}$ & $1.15 \mathrm{~d}$ & $0.48 \mathrm{c}$ & $1.63 \mathrm{~d}$ & $50.81 \mathrm{ab}$ & $34.77 \mathrm{bc}$ & $14.41 \mathrm{c}$ & $49.19 b c$ \\
\hline & N2 & $1.83 \mathrm{~b}$ & $1.21 \mathrm{c}$ & $0.54 \mathrm{~b}$ & $1.75 \mathrm{c}$ & $51.08 \mathrm{ab}$ & $33.89 \mathrm{~d}$ & $15.03 \mathrm{bc}$ & $48.92 \mathrm{bc}$ \\
\hline & N3 & $1.94 \mathrm{a}$ & $1.28 \mathrm{ab}$ & $0.56 \mathrm{ab}$ & $1.84 \mathrm{ab}$ & $51.30 \mathrm{a}$ & $33.93 \mathrm{~cd}$ & $14.77 \mathrm{bc}$ & $48.70 \mathrm{c}$ \\
\hline \multirow[t]{3}{*}{$\mathrm{S} 2$} & N1 & $1.75 \mathrm{c}$ & $1.23 \mathrm{c}$ & $0.50 \mathrm{c}$ & $1.74 \mathrm{c}$ & $50.16 \mathrm{~b}$ & $35.43 \mathrm{~b}$ & $14.41 \mathrm{c}$ & $49.84 \mathrm{~b}$ \\
\hline & $\mathrm{N} 2$ & $1.91 \mathrm{a}$ & $1.27 \mathrm{~b}$ & $0.56 \mathrm{ab}$ & $1.83 \mathrm{~b}$ & $51.05 \mathrm{ab}$ & $33.89 \mathrm{~d}$ & $15.07 \mathrm{~b}$ & $48.95 \mathrm{bc}$ \\
\hline & N3 & $1.95 \mathrm{ab}$ & $1.30 \mathrm{a}$ & $0.57 \mathrm{a}$ & $1.87 \mathrm{a}$ & $50.99 \mathrm{ab}$ & $34.07 \mathrm{~cd}$ & $14.94 \mathrm{bc}$ & $49.01 \mathrm{bc}$ \\
\hline
\end{tabular}

7 个处理的多重比较采用 LSD 法, 数据后不同小写字母表示处理间差异显著 $(P<0.05)$ 。 G：籽粒; C+S $+\mathrm{L}$ : 茎鞘 + 叶片; H+A：颖壳 +穗轴; VO: 营养器官合计。

Multiple comparisons of seven treatments were carried out using LSD method, and significant differences $(P<0.05)$ among treatments are indicated by different letters after data. G: grain; $\mathrm{C}+\mathrm{S}+\mathrm{L}$ : culm + sheath + leaf; $\mathrm{H}+\mathrm{A}$ : husk + spike axis; VO: total of vegetative organs. 
明, 增加麦季施氮量有利于提高夏玉米籽粒干物质 积累量, 但在拔节期+开花期追施氮肥条件下, 麦季 施氮量由 N2 水平增加 $25 \%$, 夏玉米籽粒干物质积累 量无显著提高, 但显著促进了营养器官干物质积累。

同一施氮量不同施氮时期处理间比较, N1、N2 和 N3 条件下, 籽粒和营养器官干物质积累量均为 $\mathrm{S} 2>\mathrm{S} 1$; 籽粒干物质分配比例在 N1 和 N2 条件下为 $\mathrm{S} 2>\mathrm{S} 1, \mathrm{~N} 3$ 条件下处理间无显著差异; 营养器官干 物质分配比例在 $\mathrm{N} 1$ 和 $\mathrm{N} 2$ 条件下为 $\mathrm{S} 1>\mathrm{S} 2$, 在 $\mathrm{N} 3$ 条件下 $\mathrm{S} 1$ 与 $\mathrm{S} 2$ 无显著差异(表 2)。因此，冬小麦拔 节期 + 开花期追氮促进了夏玉米成熟期干物质积累 量的增加, 且有利于提高中、低施氮量条件下籽粒 干物质分配比例。

2.2 麦季氮肥运筹对冬小麦-夏玉米种植体系生 物产量的影响

不施氮处理 $(\mathrm{N} 0)$ 冬小麦、夏玉米及其周年生物
产量均显著低于施氮处理(表 3)，表明不施氮肥显著 影响冬小麦-夏玉米种植体系生物产量。同一追氮时 期不同施氮量处理间比较, S1 条件下, 冬小麦、夏玉 米及其总生物产量均随麦季施氮量增加而提高, S2 条件下，也呈相同趋势，但 N3 与 N2 处理间差异不 显著。两年度试验结果表现一致(表 3)。以上结果表 明，同一追氮时期条件下，增加麦季施氮量有利于 提高夏玉米和周年生物产量; 麦季拔节期 + 开花期 追施氮肥条件下，在 $\mathrm{N} 2$ 基础上增施 $25 \%$ 氮肥对冬小 麦和夏玉米生物产量无显著促进作用。

同一施氮量不同施氮时期处理间比较, N1、N2 和 $\mathrm{N} 3$ 条件下, 冬小麦生物产量 $\mathrm{S} 2$ 与 $\mathrm{S} 1$ 无显著差异, 夏玉米生物产量为 $\mathrm{S} 2>\mathrm{S} 1$, 两年度试验结果一致(表 3)。表明麦季拔节期+开花期追施氮肥较拔节期追施 氮肥有利于提高夏玉米的生物产量, 为最终获得周 年高产奠定物质基础。

表 2 夏玉米成熟期不同器官的干物质积累量与分配比例(2010-2011)

Table 2 Dry matter accumulation and distribution proportion in different organs of summer maize at maturity (2010-2011)

\begin{tabular}{|c|c|c|c|c|c|c|c|c|c|}
\hline \multirow{2}{*}{\multicolumn{2}{|c|}{$\begin{array}{c}\text { 处理 } \\
\text { Treatment }\end{array}$}} & \multicolumn{4}{|c|}{ 积累量 Accumulation amount $\left(\mathrm{g} \mathrm{stalk}^{-1}\right)$} & \multicolumn{4}{|c|}{ 分配比例 Distribution proportion (\%) } \\
\hline & & G & $\mathrm{C}+\mathrm{S}+\mathrm{L}$ & $\mathrm{H}+\mathrm{A}$ & $\mathrm{VO}$ & G & $\mathrm{C}+\mathrm{S}+\mathrm{L}$ & $\mathrm{H}+\mathrm{A}$ & VO \\
\hline \multicolumn{2}{|c|}{ 对照 Control (N0) } & $96.34 \mathrm{e}$ & $67.07 \mathrm{e}$ & $20.54 \mathrm{e}$ & $87.61 \mathrm{e}$ & $52.36 \mathrm{~d}$ & $36.47 \mathrm{a}$ & $11.17 \mathrm{a}$ & $47.64 \mathrm{a}$ \\
\hline \multirow[t]{3}{*}{$\mathrm{S} 1$} & N1 & $152.29 \mathrm{~d}$ & $95.15 \mathrm{~d}$ & $29.81 \mathrm{~d}$ & $124.97 \mathrm{~d}$ & $54.93 \mathrm{bc}$ & $34.32 \mathrm{bc}$ & $10.75 \mathrm{ab}$ & $45.07 \mathrm{bc}$ \\
\hline & $\mathrm{N} 2$ & $160.37 \mathrm{c}$ & $103.32 \mathrm{c}$ & $32.12 \mathrm{c}$ & $135.44 \mathrm{c}$ & $54.22 \mathrm{c}$ & $34.92 \mathrm{~b}$ & $10.86 \mathrm{ab}$ & $45.78 \mathrm{~b}$ \\
\hline & N3 & $172.43 \mathrm{~b}$ & $106.21 \mathrm{bc}$ & $34.53 \mathrm{ab}$ & $140.74 \mathrm{bc}$ & $55.06 \mathrm{bc}$ & $33.92 \mathrm{c}$ & $11.02 \mathrm{ab}$ & $44.94 \mathrm{bc}$ \\
\hline \multirow[t]{3}{*}{$\mathrm{S} 2$} & N1 & $171.12 \mathrm{~b}$ & $99.90 \mathrm{c}$ & $32.48 \mathrm{bc}$ & $132.38 \mathrm{c}$ & $56.38 \mathrm{a}$ & $32.92 \mathrm{c}$ & $10.70 \mathrm{ab}$ & $43.62 \mathrm{~d}$ \\
\hline & $\mathrm{N} 2$ & $181.92 \mathrm{a}$ & $108.68 \mathrm{~b}$ & $33.86 \mathrm{abc}$ & $142.54 \mathrm{~b}$ & $56.07 \mathrm{ab}$ & $33.50 \mathrm{c}$ & $10.44 \mathrm{~b}$ & $43.93 \mathrm{~cd}$ \\
\hline & N3 & $183.37 \mathrm{a}$ & $115.23 \mathrm{a}$ & $34.77 \mathrm{a}$ & $149.99 \mathrm{a}$ & $55.01 \mathrm{bc}$ & $34.56 \mathrm{~b}$ & $10.43 \mathrm{~b}$ & $44.99 \mathrm{bc}$ \\
\hline
\end{tabular}

7 个处理的多重比较采用 LSD 法, 数据后不同小写字母表示处理间差异显著 $(P<0.05)$ 。 G：籽粒; C+S $+\mathrm{L}$ : 茎鞘 + 叶片; H+A：颖壳 +穗轴; VO: 营养器官合计。

Multiple comparisons of seven treatments were carried out using LSD method, and significant differences $(P<0.05)$ among treatments are indicated by different letters after data. G: grain; $\mathrm{C}+\mathrm{S}+\mathrm{L}$ : culm + sheath + leaf; $\mathrm{H}+\mathrm{A}$ : husk + spike axis; VO: total of vegetative organs.

表 3 冬小麦-夏玉米种植体系的生物产量

Table 3 Biomass in winter wheat-summer maize rotation system $\left(\mathrm{kg} \mathrm{hm}^{-2}\right)$

\begin{tabular}{|c|c|c|c|c|c|c|c|}
\hline \multirow{2}{*}{\multicolumn{2}{|c|}{$\begin{array}{c}\text { 处理 } \\
\text { Treatment }\end{array}$}} & \multicolumn{3}{|c|}{ 2009-2010 } & \multicolumn{3}{|c|}{ 2010-2011 } \\
\hline & & 小麦 Wheat & 玉米 Maize & 合计 Total & 小麦 Wheat & 玉米 Maize & 合计 Total \\
\hline \multicolumn{2}{|c|}{ 对照 Control (N0) } & $7810.7 \mathrm{e}$ & $10630.5 \mathrm{f}$ & $18441.2 \mathrm{e}$ & $6730.8 \mathrm{~d}$ & $11037.0 \mathrm{e}$ & $17767.8 \mathrm{~d}$ \\
\hline \multirow[t]{3}{*}{ S1 } & N1 & $13711.7 \mathrm{~d}$ & $13793.7 \mathrm{e}$ & $27505.4 \mathrm{~d}$ & $13699.3 \mathrm{c}$ & $16635.2 \mathrm{~d}$ & $30334.5 \mathrm{c}$ \\
\hline & $\mathrm{N} 2$ & $14499.3 \mathrm{bc}$ & $14395.2 \mathrm{~d}$ & $28894.5 \mathrm{c}$ & $14987.7 \mathrm{~b}$ & $17749.0 \mathrm{c}$ & $32736.7 \mathrm{~b}$ \\
\hline & N3 & $15130.3 \mathrm{ab}$ & $15211.4 \mathrm{c}$ & $30341.6 \mathrm{~b}$ & 15866.2 a & $18689.8 \mathrm{~b}$ & $34556.0 \mathrm{a}$ \\
\hline \multirow[t]{3}{*}{ S2 } & N1 & $14174.2 \mathrm{~cd}$ & $17158.2 \mathrm{~b}$ & $31332.4 \mathrm{~b}$ & $14077.7 \mathrm{c}$ & $18210.2 \mathrm{bc}$ & $32287.9 \mathrm{~b}$ \\
\hline & $\mathrm{N} 2$ & $15139.7 \mathrm{ab}$ & $19056.9 \mathrm{a}$ & $34196.6 \mathrm{a}$ & $15466.2 \mathrm{ab}$ & $19467.8 \mathrm{a}$ & $34934.0 \mathrm{a}$ \\
\hline & N3 & $15354.9 \mathrm{a}$ & $19535.1 \mathrm{a}$ & $34890.0 \mathrm{a}$ & $15964.6 \mathrm{a}$ & $20002.0 \mathrm{a}$ & $35966.6 \mathrm{a}$ \\
\hline
\end{tabular}

7 个处理的多重比较采用 LSD 法, 数据后不同小写字母表示处理间差异显著 $(P<0.05)$ 。

Multiple comparisons of seven treatments were carried out using LSD method, and significant differences $(P<0.05)$ among treatments are indicated by different letters after data. 
2.3 麦季氮肥运筹对冬小麦-夏玉米种植体系籽 粒产量的影响

不施氮肥处理冬小麦、夏玉米和周年籽粒产量 显著低于施氮处理(表 4), 表明不施氮肥显著影响籽 粒产量的积累。同一施氮时期不同施氮量处理间比 较, $\mathrm{S} 1$ 和 $\mathrm{S} 2$ 条件下, 单季或周年籽粒产量均表现为 $\mathrm{N} 2$ 与 $\mathrm{N} 3$ 显著高于 N1 处理, 但二者无显著差异(表 4)。表明同一麦季追氮时期条件下，在 N2 基础上增
施 $25 \%$ 氮肥对冬小麦和夏玉米的籽粒产量均无明显 促进作用，不利于提高氮肥的利用率。

两年度试验结果一致显示, 在 $\mathrm{N} 1$ 和 $\mathrm{N} 2$ 条件下, 冬小麦籽粒产量 $\mathrm{S} 2$ 显著大于 $\mathrm{S} 1$, 而在 $\mathrm{N} 3$ 条件下 $\mathrm{S} 2$ 与 $\mathrm{S} 1$ 无显著差异; 同一施氮量条件下, 夏玉米和周 年籽粒产量均为 S2>S1 (表 4)。表明与拔节期追施氮 肥相比，拔节期+开花期追施氮肥不仅有利于提高冬 小麦籽粒产量, 且明显促进夏玉米籽粒产量的增加。

表 4 冬小麦-夏玉米种植体系的籽粒产量

Table 4 Grain yields in winter wheat-summer maize rotation system $\left(\mathrm{kg} \mathrm{hm}^{-2}\right)$

\begin{tabular}{|c|c|c|c|c|c|c|c|}
\hline \multirow{2}{*}{\multicolumn{2}{|c|}{$\begin{array}{c}\text { 处理 } \\
\text { Treatment }\end{array}$}} & \multicolumn{3}{|c|}{$2009-2010$} & \multicolumn{3}{|c|}{$2010-2011$} \\
\hline & & 小麦 Wheat & 玉米 Maize & 合计 Total & 小麦 Wheat & 玉米 Maize & 合计 Total \\
\hline 对照 & Control (N0) & $4492.7 \mathrm{~d}$ & $6000.0 \mathrm{e}$ & $10492.7 \mathrm{e}$ & $3002.5 \mathrm{e}$ & $5887.9 \mathrm{f}$ & $8890.4 \mathrm{f}$ \\
\hline \multirow[t]{3}{*}{ S1 } & N1 & $6829.5 \mathrm{c}$ & $8160.0 \mathrm{~d}$ & $14989.5 \mathrm{~d}$ & $6840.2 \mathrm{~d}$ & $9175.0 \mathrm{e}$ & $16015.2 \mathrm{e}$ \\
\hline & $\mathrm{N} 2$ & $7389.2 \mathrm{~b}$ & $8520.0 \mathrm{~cd}$ & $15909.2 \mathrm{c}$ & $7453.2 \mathrm{bc}$ & $10024.4 \mathrm{~cd}$ & $17477.6 \mathrm{~cd}$ \\
\hline & N3 & $7631.4 \mathrm{ab}$ & $8853.3 \mathrm{c}$ & $16484.7 \mathrm{bc}$ & $7830.2 \mathrm{ab}$ & $10264.1 \mathrm{bc}$ & $18094.3 \mathrm{bc}$ \\
\hline \multirow[t]{3}{*}{$\mathrm{S} 2$} & N1 & $7420.3 \mathrm{~b}$ & $9800.0 \mathrm{~b}$ & $17220.3 \mathrm{~b}$ & $7319.5 \mathrm{c}$ & $9910.0 \mathrm{~d}$ & $17229.5 \mathrm{~d}$ \\
\hline & $\mathrm{N} 2$ & $7794.4 \mathrm{a}$ & $10706.7 \mathrm{a}$ & $18501.1 \mathrm{a}$ & $7956.5 \mathrm{a}$ & $10677.1 \mathrm{ab}$ & $18633.6 \mathrm{ab}$ \\
\hline & N3 & $7837.2 \mathrm{a}$ & $10840.0 \mathrm{a}$ & $18677.2 \mathrm{a}$ & $8040.2 \mathrm{a}$ & $10853.0 \mathrm{a}$ & $18893.3 \mathrm{a}$ \\
\hline
\end{tabular}

7 个处理的多重比较采用 LSD 法, 数据后不同小写字母表示处理间差异显著 $(P<0.05)$ 。

Multiple comparisons of seven treatments were carried out using LSD method, and significant differences $(P<0.05)$ among treatments are indicated by different letters after data.

\section{4 麦季氮肥运筹对冬小麦-夏玉米种植体系氮} 肥农学利用率的影响

麦季氮肥运筹对夏玉米的氮肥农学利用率存在 显著调控效应，同一追氮时期条件下，随施氮量增 加，麦季氮肥农学利用率显著降低; 麦季不同追氮 方式对玉米季氮肥农学利用率影响不同, S1 条件下, 随麦季施氮量增加玉米季氮肥农学利用率显著提高 $(P<0.05), \mathrm{S} 2$ 条件下则表现为 $\mathrm{N} 2 、 \mathrm{~N} 3>\mathrm{N} 1$ 。 $\mathrm{S} 1$ 条件 下, 周年氮肥农学利用率以 $\mathrm{N} 2$ 处理最高, 其次为 $\mathrm{N} 1$ 处理, N3 处理最低; S2 条件下, 周年氮肥农学利 用率则表现为 $\mathrm{N} 2$ 和 $\mathrm{N} 1$ 处理显著大于 $\mathrm{N} 3$ 处理(图 1)。 这说明随麦季施氮量的增加, 麦季氮肥农学利用率 逐渐降低, 但在玉米季则有所提高; 在拔节期+开花 期追施氮肥条件下, 施氮量由 $\mathrm{N} 2$ 水平增加 $25 \%$ 对玉 米季氮肥农学利用率无显著促进作用, 不利于提高 周年氮肥农学利用率。

$\mathrm{N} 1$ 和 N2 条件下麦季氮肥农学利用率为 $\mathrm{S} 2>\mathrm{S} 1$, $\mathrm{N} 3$ 条件下 S2 虽高于 S1, 但无显著差异。N1、N2 和 N3 条件下, 玉米季和周年氮肥农学利用率均为 S2 $>$ S1 (图 1)。表明与拔节期追施氮肥相比, 麦季拔 节期+开花期追施氮肥不仅有利于提高麦季氮肥农 学利用率, 亦促进夏玉米对氮肥的吸收利用, 有利 于提高残留氮肥的利用率。

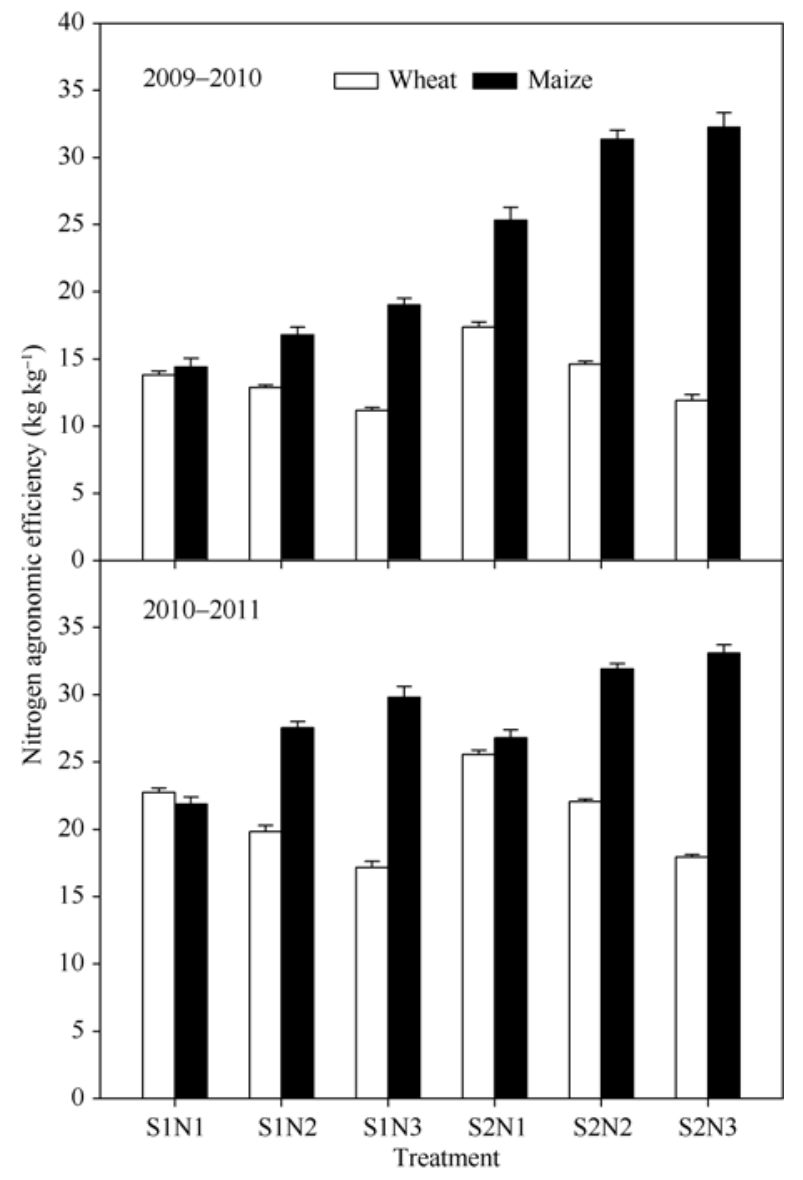

图 1 冬小麦-夏玉米体系的氮肥农学利用率

Fig. 1 Nitrogen agronomic use efficiency in winter wheat-summer maize rotation system 


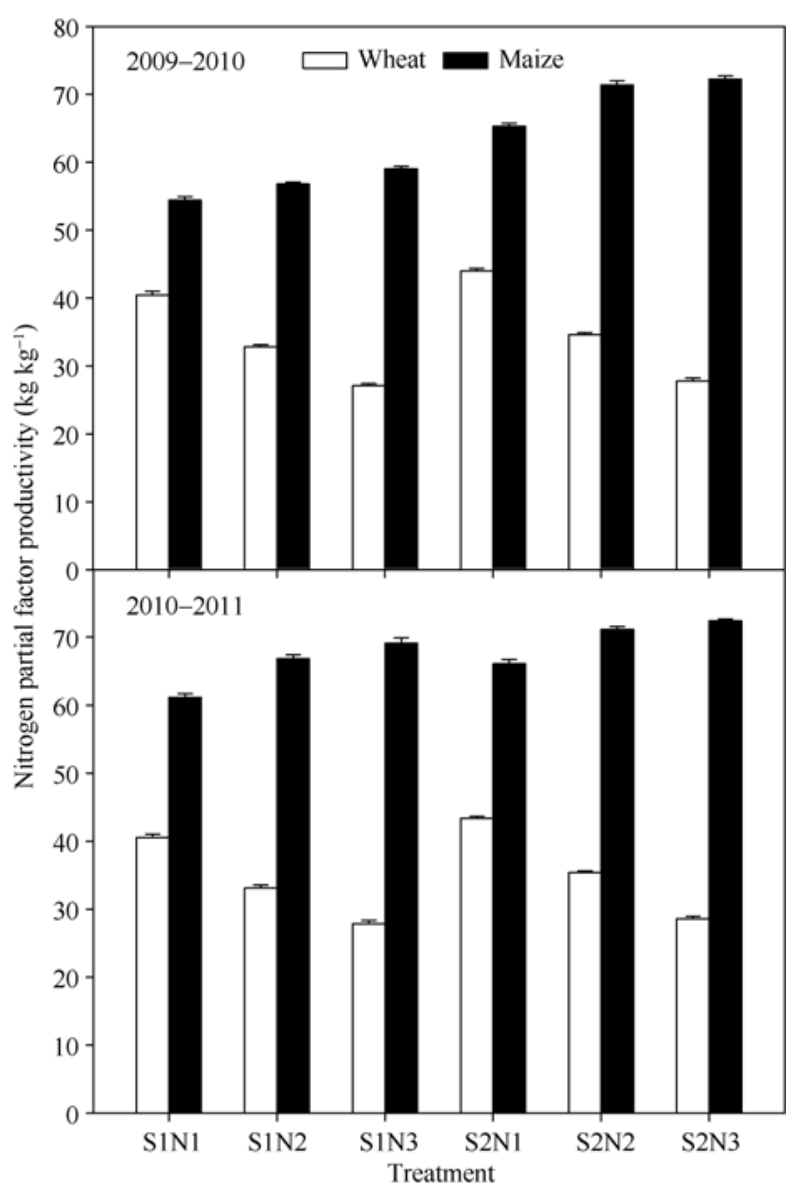

图 2 冬小麦-夏玉米体系的氮肥偏生产力

Fig. 2 Nitrogen partial factor productivity in winter wheat-summer maize rotation system

2.5 麦季氮肥运筹对冬小麦-夏玉米种植体系氮 肥偏生产力的影响

两年度试验结果表明, 麦季施氮量和追氮时期 显著调控玉米季的氮肥偏生产力, 进而影响周年氮 肥偏生产力。同一施氮时期不同施氮量处理间比较, $\mathrm{S} 1$ 和 $\mathrm{S} 2$ 条件下, 麦季氮肥偏生产力随施氮量增加 显著降低。玉米季氮肥偏生产力两年度表现不同, S1 条件下, 随麦季施氮量增加, 玉米季氮肥偏生产力 逐渐提高, 在 2009-2010 年度 N2 与 N1、N3 均无 显著差异, 但 $N 3$ 显著高于 N1, 2010-2011 年度则为 $\mathrm{N} 3$ 和 N2 显著高于 N1; S2 条件下, 两年度试验结果 均表现为 $\mathrm{N} 3$ 和 $\mathrm{N} 2$ 显著高于 $\mathrm{N} 1$ 。周年氮肥偏生产 力随麦季施氮量增加显著降低, 两年度结果一致(图 2)。以上结果表明增加麦季施氮量不利于提高麦季 和周年氮肥偏生产力, 但促进玉米季氮肥偏生产力 的升高; 但在拔节期 + 开花期追施氮肥条件下, 施氮 量由 N2 水平增加 $25 \%$ 对玉米季氮肥偏生产力无显 著影响。

同一施氮量不同施氮时期处理间比较，麦季氮
肥偏生产力在 $\mathrm{N} 1$ 和 $\mathrm{N} 2$ 条件下为 $\mathrm{S} 2>\mathrm{S} 1 ; \mathrm{N} 3$ 条件下 亦以 $\mathrm{S} 2$ 较高, 但 $\mathrm{S} 2$ 与 $\mathrm{S} 1$ 无显著差异; 玉米季和周 年氮肥偏生产力 $\mathrm{N} 1 、 \mathrm{~N} 2$ 和 $\mathrm{N} 3$ 条件下均为 $\mathrm{S} 2>\mathrm{S} 1$ 。 两年度试验结果一致(图 2)。表明与拔节期追施氮肥 相比, 麦季拔节期 + 开花期追施氮肥不仅有利于提 高麦季氮肥偏生产力, 而且也提高玉米季氮肥偏生 产力, 促进夏玉米对残留氮肥的利用。

\section{3 讨论}

Sampaio 等 ${ }^{[16]}$ 研究指出, 后茬作物对土壤残留 氮素的利用是有限的, 并与土壤水分、质地、气温 等因素有关 ${ }^{[17]}$ 。冬小麦收获后 $0 \sim 90 \mathrm{~cm}$ 土层土壤残 留无机氮与下茬夏玉米的籽粒产量呈显著的线性加 平台的关系, 夏玉米在达到平台产量时的土壤残留 无机氮为 $63.6 \mathrm{~kg} \mathrm{hm}^{-2}{ }^{[18]}$ 。本试验发现麦季施氮量 对冬小麦和夏玉米生物产量和籽粒产量的调控效应 在不同追氮时期条件下表现不同。在拔节期追施氮 肥条件下，随麦季施氮量增加，夏玉米和周年生物 产量显著提高, 冬小麦生物产量 N2 与 $\mathrm{N} 3$ 无显著差 异; 在拔节期+开花期追施氮肥条件下, 冬小麦和夏 玉米的生物产量表现为 N2 与 N3 无显著差异。同一 追氮时期条件下，冬小麦和夏玉米的籽粒产量均表 现为 N2 与 N3 无显著差异。与拔节期追施氮肥相比, 拔节期 + 开花期追施氮肥不仅提高了冬小麦的生物 产量与籽粒产量, 亦促进了夏玉米生物产量和籽粒 产量的增加, 有利于提高氮肥的利用率。以上结果 表明, 麦季施氮量为 $225 \mathrm{~kg} \mathrm{hm}^{-2}$, 在拔节期+开花期 追氮是确保冬小麦-夏玉米种植体系实现高产的适 宜麦季施氮量和追氮时期。

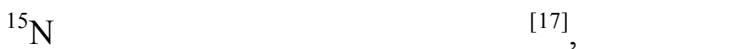
之后的残留氮约占施氮量的 $15 \% \sim 30 \%$, 甚至更多 ${ }^{[19]}$ 。 残留氮的比例因作物、氮肥种类、肥料施用量和施 用方法的不同有很大差异 ${ }^{[20]}$ 。一般认为, 后作对氮 肥利用率比第 1 季作物的利用率要低得多。氮肥在 第 1 年的利用率多在 $40 \%$ 左右, 第 2 年以后的利用 率只占最初施氮量的 $1 \% \sim 10 \%{ }^{[21-23]}$ 。因而认为残留 肥料氮对后茬作物氮素养分的贡献是有限的。但对 冬小麦-夏玉米轮作体系而言, 前后茬间隔时间短, 冬小麦氮肥残效可能对夏玉米有较大影响。本试验 结果表明, 随麦季施氮量的增加, 麦季氮肥农学利 用率和氮肥偏生产力逐渐降低, 玉米季的则提高, 但在麦季拔节期+开花期追施氮肥条件下，施氮量 由 $225 \mathrm{~kg} \mathrm{hm}^{-2}$ (N2)增加 $25 \%$, 玉米季氮肥农学利用 
率和氮肥偏生产力无显著升高。与拔节期追施氮肥 相比, 拔节期+开花期追施氮肥不仅有利于提高麦 季氮肥农学利用率, 亦促进了玉米季对氮肥的利 用。麦季施氮 $225 \mathrm{~kg} \mathrm{hm}^{-2}$ 并采用拔节期和开花期追 氮方式是确保冬小麦-夏玉米种植体系实现高效的 适宜氮肥运筹模式。

干物质积累是作物器官分化、产量形成的前提, 养分吸收是干物质形成和累积的基础 ${ }^{[24]}$ 。氮供应与 光合生产直接相关, 氮供应很低时, 干物质, 特别 是叶片干物质量降低, 而叶片干物质量的减少影响 了光合生产和再生器官内同化物的分布 ${ }^{[25]}$ 。干物质 在营养器官积累的多寡, 以及开花后向籽粒转运分 配的比率, 都直接影响粒重和产量 ${ }^{[26]}$ 。有研究表明, 随施氮量的增加, 冬小麦各生育期干物质积累量增 大 $^{[27]}$; 适量施氮明显促进夏玉米籽粒干物质积累, 而施氮不足或过量都影响籽粒发育 ${ }^{[28]}$ 。本研究发现, 麦季拔节期追施氮肥条件下, 增加施氮量不仅提高 了冬小麦籽粒和营养器官干物质积累量, 也促进了 夏玉米籽粒干物质积累; 拔节期+开花期追施氮肥 条件下，麦季施氮量由 $225 \mathrm{~kg} \mathrm{hm}^{-2}$ 增加 $25 \%$ 对冬小 麦和夏玉米籽粒干物质积累无明显促进作用。冬小 麦干物质积累量对追氮时期的响应与夏玉米存在差 异。在中 (N2)、低(N1)施氮量条件下，与拔节期追氮 相比, 拔节期+开花期追氮提高了冬小麦籽粒和营 养器官的干物质积累量, 但在高施氮量(N3)条件下, 冬小麦籽粒和营养器官干物质积累量对追氮时期反 应不敏感; 而夏玉米籽粒和营养器官干物质积累量 在各麦季施氮量条件下均为 $\mathrm{S} 2>\mathrm{S} 1$ 。可见, 麦季拔节 期 + 开花期追氮较拔节期追氮促进了夏玉米的物质 积累, 但关于麦季氮肥运筹调控夏玉米干物质积累 与分配的生理机制有待进一步研究。

\section{4 结论}

麦季施氮量显著调控后茬玉米季的物质积累和 氮素利用, 进而影响周年物质生产和氮肥利用率, 且不同追氮时期条件下的调控效应存在差异。在麦 季追氮时期相同的条件下, 施氮量由 $225 \mathrm{~kg} \mathrm{hm}^{-2}$ 增 加 $25 \%$, 冬小麦和夏玉米的籽粒产量均无显著变化; 随施氮量增加, 麦季氮肥农学利用率和氮肥偏生产 力显著降低, 玉米季氮肥农学利用率逐渐升高, 但 玉米季氮肥偏生产力在施氮 $225 \mathrm{~kg} \mathrm{hm}^{-2}$ 和 281.25 $\mathrm{kg} \mathrm{hm}^{-2}$ 处理间差异不显著。麦季拔节期+开花期追 施氮肥比仅拔节期追施增加夏玉米生物产量和籽粒 产量, 提高氮肥农学利用率和氮肥偏生产力。在冬
小麦-夏玉米种植体系与本试验条件接近的地区, 建议麦季总施氮量 $225 \mathrm{~kg} \mathrm{hm}^{-2}$, 在部分基施的基础 上, 分拔节期和开花期两次追施, 可获得双季高产 和高氮肥利用率。

\section{References}

[1] Zhang Y-S(张银锁), Yu Z-R(宇振荣), Driessen P M. Experimental study of assimilate production, partitioning and translocation among plant organs in summer maize (Zea mays) under various environmental and management conditions. Acta Agron Sin (作物 学报), 2002, 28(1): 104-109 (in Chinese with English abstract)

[2] Wang D-M(王德梅), Yu Z-W(于振文), Zhang Y-L(张永丽), Wang $\mathrm{D}$ (王东). Effects of irrigation on dry matter production and water use of different wheat cultivars. $J$ Triticeae Crops (麦类作 物学报), 2010, 30(2): 366-371 (in Chinese with English abstract)

[3] Duan W-X(段文学), Yu Z-W(于振文), Zhang Y-L(张永丽), Wang $\mathrm{D}$ (王东). Effects of supplemental irrigation on water consumption characteristics and dry matter accumulation and distribution in different spike-type wheat cultivars based on testing soil moisture. Chin J Plant Ecol (植物生态学报). 2010, 34(12): 1424- 1432 (in Chinese with English abstract)

[4] Wang Y-J(王永军), Sun Q-Z(孙其专), Yang J-S(杨今胜), Wang K-J(王空军), Dong S-T(董树亭), Yuan C-P(袁翠平), Wang L-C(王立春). Effects of controlled-release urea on yield and photosynthesis characteristics of maize (Zea mays L.) under different soil fertility conditions. Acta Agron Sin (作物学报), 2011, 37(12): 2233-2240 (in Chinese with English abstract)

[5] Liu Y-H(刘永红), Yang Q(杨勤), Yang W-Y(杨文铨), Gao Q(高 强), He W-Z(何文铸), Ke G-H(柯国华). Effect of soil drying wetting alternation on dry biomass accumulation and reallocation at maize flowering stage. Acta Agron Sin (作物学报), 2006, 32(11): 1723-1727 (in Chinese with English abstract)

[6] Demotes-Mainarda S, Jeuffroy M-H. Effects of nitrogen and radiation on dry matter and nitrogen accumulation in the spike of winter wheat. Field Crop Res, 2004, 87: 221-233

[7] Zhang F-Q(张法全), Wang X-Y(王小燕), Yu Z-W(于振文), Wang X-Z(王西芝), Bai H-L(白洪立). Characteristics of accumulation and distribution of nitrogen and dry matter in wheat at yield level of ten thousand kilograms per hectare. Acta Agron Sin (作物学报), 2009, 35(6): 1086-1096 (in Chinese with English abstract)

[8] Li Q-J(李青军), Zhang Y(张炎), Hu W(胡伟), Meng F-X(孟凤 轩), Feng G-P(冯广平), Hu G-Z(胡国智), Liu X-L(刘新兰). Effects of nitrogen management on maize dry matter accumulation, nitrogen uptake and distribution and maize yield. Plant Nutr Fert Sci (植物营养与肥料学报), 2011，17(3): 755-760 (in Chinese with English abstract)

[9] Shan Y-S(单玉珊), Mu M-C(慕美财), Han S-L(韩守良), Shan C-G(单成钢), Pang J-M(逢吉敏). Studies on the mathematical model of the comprehensive effects of soil, fertilizer and water in the one-year-two-crop system of wheat and maize. Sci Agric Sin 
(中国农业科学)，1996，29(2): 34-44 (in Chinese with English abstract)

[10] Zhang L-J(张丽娟), Ju X-T(巨晓棠), Zhang F-S(张福锁), Peng $\mathrm{Z}-\mathrm{P}$ (彭正萍). Movement and residual effect of labeled nitrate-N in different soil layers. Sci Agric Sin (中国农业科学), 2007, 40(9): 1964-1972 (in Chinese with English abstract)

[11] Davis J H, Griffith S M, Horwath W R, Steiner J J, Myrold D D. Fate of nitrogen-15 in a perennial ryegrass seed field and herbaceous riparian area. Soil Sci Soc Am J, 2006, 70: 909-919

[12] Matar A E, Pala M, Beck D, Garabet S. Nitrate-N test as a guide to $\mathrm{N}$ fertilization of wheat in the Mediterranean region. Commun Soil Sci Plant Anal, 1990, 21: 1117-1130

[13] Frederick R M, William E J, Richard H F, Gary F G. A soil test for nitrogen availability in the northeastern United States. Commun Soil Sci Plant Anal, 1990, 21: 1103-1115

[14] Arvind K S, Jagdish K L, Singh V K, Dwivedi B S. Calibrating the leaf color chart for nitrogen management in different genotypes of rice and wheat in a system perspective. Agron J, 2004, 96: $1606-1621$

[15] Ye Q-B(叶全宝), Zhang H-C(张洪程), Wei H-Y(魏海燕), Zhang $\mathrm{Y}$ (张瑛), Wang B-F(汪本福), Xia K(夏科), Huo Z-Y(霍中洋), Dai Q-G(戴其根), Xu K(许轫). Effects of nitrogen fertilizer on nitrogen use efficiency and yield of rice under different soil conditions. Acta Agron Sin (作物学报), 2005, 31(11): 1422-1428 (in Chinese with English abstract)

[16] Sampaio E V S B, Tiessen H, Antonino A C D, Salcedo I H. Residual $\mathrm{N}$ and $\mathrm{P}$ fertilizer effect and fertilizer recovery on intercropped and sole-cropped corn and bean in semiarid northeast Brazil. Nutr Cycl Agroecosys, 2004, 70: 1-11

[17] Corbeels M, Hofman G, Van Cleemput O. Residual effect of nitrogen fertilization in a wheat-sunflower cropping sequence on a vertisol under semi-arid Mediterranean conditions. Eur J Agron, 1998, 9: 109-116

[18] Huang S-B(黄生斌), Chen X-P(陈新平), Zhang F-S(张福锁). Effect of residual nitrogen applied to winter wheat on the following summer maize. J China Agric Univ (中国农业大学学报), 2002, 7(1): 54-58 (in Chinese with English abstract)

[19] Huang D-M(黄东迈), Zhu P-L(朱培立), Gao J-H(高家骅). Residual effect of organic and inorganic fertilizer nitrogen in paddy and dryland. Sci Sin (Ser B) (中国科学 B 辑), 1982, 12(10):
907-910 (in Chinese)

[20] Tong Y-P(童依平), Li J-Y(李继云), Liu Q-Y(刘全友), Sun $\mathrm{J}-\mathrm{H}$ (孙建华). Variations of residual nitrate in the soil grown different wheat genotypes after harvest. Acta Sci Circumst (环境科 学学报), 2000, 20(2): 251-253 (in Chinese with English abstract)

[21] Li Z-H(李志宏), Wang X-R(王兴仁), Cao Y-P(曹一平). The quantitative study of nitrogen residual effect under wheat-corn rotating system. J Beijing Agric Univ (北京农业大学学报), 1995, 21(suppl): 29-32 (in Chinese with English abstract)

[22] Zhao Z-D(赵振达), Zhang J-S(张金盛), Ren S-R(任顺荣), Zhou Y-M(周艺敏). The nitrogen balance of crop field soil in north area of China. Acta Agric Boreali-Sin (华北农学报), 1988, 3(4): 67-72 (in Chinese with English abstract)

[23] Li G-R(李光锐). Using tracer isotope to study the interrelation of $\mathrm{N}$ and $\mathrm{P}$ during mixed application of ammonium sulphate and superphospnate to crops. Sci Agric Sin (中国农业科学), 1982, 15(2): 63-71 (in Chinese with English abstract)

[24] Song H-X(宋海星), Li S-P(李生秀). Dynamics of nutrient accumulation in maize plants under different water and $\mathrm{N}$ supply conditions. Sci Agric Sin (中国农业科学), 2003, 36(1): 71-76 (in Chinese with English abstract)

[25] Dordas C A, Lithourgidis A S, Matsi T, Barbayiannis N. Application of liquid cattle manure and inorganic fertilizers affect dry matter, nitrogen accumulation, and partitioning in maize. Nutr Cycl Agroecosyst, 2008, 80: 283-296

[26] Zhang J-H(张均华), Liu J-L(刘建立), Zhang J-B(张佳宝), Zhao F-T(赵夫涛), Cheng Y-N(程亚南), Wang W-P(王伟鹏). Effects of nitrogen application rates on translocation of dry matter and utilization of nitrogen in rice and wheat. Acta Agron Sin (作物学 报), 2010, 36(10): 1736-1742 (in Chinese with English abstract)

[27] Guo D(郭栋), Dang T-H(党廷辉), Qi L-H(戚龙海). Process study of dry matter accumulation and nitrogen absorption use of winter wheat under different $\mathrm{N}$-fertilizer rates on dry highland of loess plateau. J Soil Water Conserv (水土保持学报), 2008, 22(5): 138-141 (in Chinese with English abstract)

[28] Shen L-X(申丽霞), Wei Y-P(魏亚萍), Wang P(王璞), Yi Z-X(易 镇邪), Zhang H-F(张红芳), Lan L-W(兰林旺). Effect of nitrogen supply on early kernel development and yield in summer maize (Zea mays L.). Acta Agron Sin (作物学报), 2006, 32(11): 1746-1751 (in Chinese with English abstract) 